\title{
1 The mechanism underlying J-waves and T-waves in the electrocardiogram of \\ 2 mice and zebra finches
}

5 Joost A. Offerhaus ${ }^{1}$, Peter C. Snelderwaard ${ }^{3}$, Jaeike W. Faber ${ }^{2}$, Katharina Riebe ${ }^{3}$, Bjarke Jensen ${ }^{* 2}$, Bas

6 J. Boukens ${ }^{* 1,2}$.

$7 \quad *$ These authors contributed equally

9 1) Department of Experimental Cardiology, Academic Medical Center, Amsterdam University 10 Medical Center, Amsterdam, Netherlands

11 2) Department of Medical Biology, Academic Medical Center, Amsterdam University Medical Center, 12 Amsterdam, Netherlands

13 3) Institute of Biology, Leiden University, $2333 \mathrm{BE}$, Leiden, The Netherlands

Keywords: Zebra finch, early repolarization, high heart rates, optical mapping, birds

Summary statement: Zebra finches are small birds with high heart rates. Similar to small rodents, the 19

zebra finch ECG contains a J-wave, which is caused by early repolarization

Corresponding authors:

Bastiaan J. Boukens, Ph.D.

Department of Medical Biology

Academic Medical Center

University of Amsterdam

Meibergdreef 15, Room L2-106

1105 AZ Amsterdam

The Netherlands

Tel: +31 (0)20 5664659

Email: $\underline{\text { b.j.boukens@amsterdamumc.nl }}$
Bjarke Jensen, PhD

Department Medical Biology

Academic Medical Center

University of Amsterdam

Meibergdreef 15, Room L2-106

1105 AZ Amsterdam

The Netherlands

Tel: +31 (0)205664659

Email: b.jensen@amsterdamumc.nl 


\section{Abstract}

22 Brief cardiac cycles are required to achieve high heart rates as seen in endothermic animals.

23 A main determinant of the cardiac cycle is the repolarization phase of the cardiac action

24 potential, which is visible in the ECG as a T-wave. In mammals with high heart rates - such

25 as rodents - the repolarization phase is short and the ECG is characterized by a positive

26 deflection following the QRS-complex, the J-wave. It is unclear whether birds with high

27 heart rates show similar ECG characteristics. Here we study cardiac repolarization and the

28 ECG in the zebra finch which has high heart rates. In ex vivo hearts of zebra finch $(\mathrm{N}=5)$ and mouse ( $\mathrm{N}=5$ ), pseudo-ECGs and optical action potentials were measured. In both species,

30 total ventricular activation was fast with QRS durations shorter than $10 \mathrm{~ms}$. Ventricular

31 activation progressed from the left to the right ventricle in zebra finch whereas the

32 activation pattern was apex-to-base in mouse. In both species, phase 1 early repolarization

33 followed the activation front, causing a positive J-wave in the pseudo-ECG. In zebra finch,

34 late repolarization was directed from the right ventricle to the left ventricle, whereas late

35 repolarization was directed opposite in mouse. Accordingly, on the zebra finch ECG, the J-

36 wave and the T-wave have the same direction, whereas in the mouse the J-wave and the T-

37 wave are discordant. Our findings demonstrate early repolarization and the associated J-

38 wave are not restricted to mammals and that they also occur within birds. Early

39 repolarization may have evolved by convergence in association with high heart rates. 
40

41

42

43

44

45

46

47

\section{Introduction}

High heart rates distinguish the hearts of mammals and birds from the hearts of ectothermic vertebrates (Hillman and Hedrick, 2015). The high heart rates are required to drive the great cardiac output required to sustain the highly energetically demanding state of endothermy (Crossley et al., 2016; Boukens et al., 2019). To sustain high heart rates brief cardiac cycles are essential. The main determinant of the cardiac cycle is the repolarization phase of the cardiac action potential. During the repolarization phase, the cardiomyocyte is refractory or unexcitable, which is necessary to reset the intracellular calcium homeostasis. Regional differences in duration of the repolarization phase cause the formation of a T-wave on the electrocardiogram (ECG). The QT-interval is thereby an estimate for the duration of repolarization. Across mammalian species, repolarization differences exist (Durrer et al., 1970; Boukens et al., 2013; Opthof et al., 2017). For example, compared to humans, the action potential of mice is much shorter. In addition, the phase-1 repolarization is large and the plateau phase is absent. Consequently, the mouse ECG is without the isoelectric STsegment that in humans coincides with the plateau phase of the action potential. Instead, the murine early repolarization is visible on the ECG as a positive deflection directly following the QRS complex (Opthof, 2000). This so-called J-wave is seen in many species of rodents and is therefore sometimes also referred to as the rodent J-wave.

Not all rodent ECGs, however, exhibit a J-wave and the Capybara, the largest rodent on earth, exemplifies this (Szabuniewicz et al., 2010). Additionally, in other small non-rodent mammals, such as shrews and bats, J-waves have also been found (Nagel, 1986; Currie, 2018). Despite the difference in phylogenetic origin, these small mammals all share high heart rates that drive the great cardiac output required to sustain their greater massspecific metabolic rates (Lillywhite, Zippel and Farrell, 1999; Burggren, Farrell and Lillywhite, 2011). In order to maintain a high heart rate, cardiomyocytes must be excitable when the next cardiac cycle arrives. For this, shortening of the action potential is crucial in order to overcome refractoriness and thereby ensuring excitability. Therefore, the cardiomyocyte must adapt by repolarizing fast. This phenomenon is also reflected by the negative relationship between the QT interval on the ECG and heart rate (Bazett, 1920).

If early repolarization is an adaptation to high heart rates, rather than a rodent specific trait, we also expected to find it in the hearts of other endothermic animals with high heart rates (Lillywhite, Zippel and Farrell, 1999). A variety of studies have looked at the electrocardiographic characteristics of different bird species (Table 1). From these studies, not all bird species exhibit a clear isoelectric ST segment, which can be due to early repolarization (Nap, Lumeij and Stokhof, 1992; Cinar et al., 1996; Lopez Murcia et al., 2005; Szabuniewicz and McCrady, 2010; Hassanpour and Khadem, 2013; Hassanpour et al., 2014, 2016). In the absence of recorded action potentials, however, early repolarization has not been shown in any of these studies. In the current study, we electrically characterized the heart of the zebra finch, a small bird with high heart rate ( $600-700 \mathrm{bpm})$, by recordings of ECG and action potentials and with comparisons to the mouse heart to see if these small birds also show early repolarization (Cooper and Goller, 2006). 
81 Material and Methods

\section{Methods}

\section{Isolation of hearts}

84 Avian subjects were five zebra finches (Taeniopygia guttata,) three females (age: ), two males (mean age 49.0 days \pm 0.8 , mean body weight $18.0 \mathrm{~g}, \pm 1.1$ ) from the breeding colony at Leiden University. These birds were obtained at three different instances, whenever birds were culled at the colony (independent of this study). After catching the birds were immediately and swiftly killed by cervical dislocation. Immediately following the cervical dislocation, the rib cage was cut laterally and the ventral part was lifted up. The heart was lifted by grapping lung tissue with forceps and the heart was excised by cuts to the lungs, veins, and arteries. At all times, we strove to avoid touching and damaging the heart chambers. The heart was then transferred to a petri dish containing cold cardioplegic solution, containing (mM): $\mathrm{NaCl}, 110 ; \mathrm{CaCl}_{2}, 1.2 ; \mathrm{KCl}, 16 ; \mathrm{MgCl}_{2}, 16 ; \mathrm{NaHCO}_{3}, 10$; and glucose, 9.01 at $4^{\circ} \mathrm{C}$. A cannula was inserted in one of the 3 main branches of the aorta and fastened by a suture surrounding all 3 trunks. The arterial pole and coronary vessels were then flushed with ice-cold cardioplegic solution. The procedure from cervical dislocation to the flushing of the coronary vasculature took approximately $5 \mathrm{~min}$. Once the coronary vessels were flushed, excess non-cardiac tissue was trimmed off and the heart was placed in a reservoir of ice-cold cardioplegic solution and kept there during transport from Leiden to Amsterdam ( $\pm 45 \mathrm{~min}$ ).

101 The use post mortem material of animals culled as breeding surplus is not considered a procedure on itself in accordance with the Experiments on Animals Act (Wod, 2014). This is the applicable legislation in the Netherlands in accordance with the European guidelines (EU directive no. 2010/63/EU) regarding the protection of animals used for scientific purposes.

105 Therefor a license was not obtained for the procedure. All zebra finches were however

106 housed and cared for in accordance to these regulations and internal guidelines concerning 107 care of the animals and licensing and skill of personnel. This also includes that advise is 108 taken from the animal welfare body Leiden to minimize suffering for all animals at the facility (with or without a license).

110 Five mice (Mus musculus) were used (FVB/NRj background, male, mean age 3.3 months, \pm 111 0.1) for the experiments. Mice were kept at the Amsterdam University Medical Center 112 (AUMC) animal breeding unit and had ad libitum access to Teklad 2916 chow (Envigo, 113 Huntingdon, UK) and water. On the morning of the experiment, the mice were moved alive 114 to the department of Experimental Cardiology. Starting the experiment mice were 115 anesthetized by gradually increasing $\mathrm{CO}_{2}$ and were sacrificed through cervical dislocation. 116 Mice hearts were excised and the aorta cannulated, in a similar manner as the zebra finch. 117 All mice experimental procedures reported here were in accordance with governmental and 118 institutional guidelines and were approved by the local animal ethics committee of the 119 AUMC.

120

121 Optical mapping 
122 The isolated zebra finch hearts were transported from Leiden University to the Department

123 of Experimental Cardiology of the Academic Medical Center in Amsterdam. The zebra finch

124 and mouse hearts were mounted on a Langendorff perfusion setup, and perfused at $37^{\circ} \mathrm{C}$

125 with Tyrode's solution $(128 \mathrm{mmol} / \mathrm{L} \mathrm{NaCl}, 4.7 \mathrm{mmol} / \mathrm{L} \mathrm{KCl}, 1.45 \mathrm{mmol} / \mathrm{L} \mathrm{CaCl} 2,0.6 \mathrm{mmol} / \mathrm{L}$

$126 \mathrm{MgCl}_{2}, 27 \mathrm{mmol} / \mathrm{L} \mathrm{NaHCO}, 0.4 \mathrm{mmol} / \mathrm{L} \mathrm{NaH}{ }_{2} \mathrm{PO}_{4}$, and $11 \mathrm{mmol} / \mathrm{L}$ glucose $(\mathrm{pH}$ maintained at

1277.4 by equilibration with a mixture of $95 \% \mathrm{O} 2$ and $\left.5 \% \mathrm{CO}_{2}\right)$ ), containing blebbistatin to

128 prevent movement artifacts. After a recovery period of $\sim 10 \mathrm{~min}$ the hearts received a bolus

129 injection of $20 \mu \mathrm{M}$ Di-4 ANEPPS. 3-lead ex vivo ECGs were recorded (Biosemi, Amsterdam,

130 the Netherlands; sampling rate $2048 \mathrm{~Hz}$, filtering $\mathrm{DC} 400 \mathrm{kHz}(3 \mathrm{~dB})$ ) and analyzed using

131 LabChart Pro (by Mitchells formula). A standard six-lead ECG was calculated as follows: I = L-

$132 \mathrm{R}, \mathrm{II}=\mathrm{F}-\mathrm{R}, \mathrm{III}=\mathrm{F}-\mathrm{L}, \mathrm{aVR}=\mathrm{R}-(\mathrm{L}+\mathrm{F}) / 2, \mathrm{aVL}=\mathrm{L}-(\mathrm{R}+\mathrm{F}) / 2$, and $\mathrm{aVF}=\mathrm{F}-(\mathrm{L}+\mathrm{R}) / 2$. Activation and

133 repolarization patterns were measured during sinus rhythm and atrial pacing at a basic cycle

134 length of $120 \mathrm{~ms}$ (twice the diastolic stimulation threshold).

135

136 Analysis

137 Optical signals were analyzed using custom made software (Laughner et al., 2012) based on

138 Matlab2018. Local moment of activation was defined as the maximum positive $\mathrm{dV} / \mathrm{dt}$ of the 139 depolarization phase of the action potential. One zebra finch was excluded from 140 repolarization analysis because of movement artefacts. Repolarization times were taken 141 from 20 and 80 percent of the amplitude of 10 averaged optical signals. Pseudo-ECGs and 142 optical action potentials were simultaneously recorded and aligned by the start of the 143 optical recording. Start of the QRS complex was taken as point zero.

\section{Statistics}

146 Variables were presented as mean \pm s.e.m. and compared using a two-way analysis of 147 variance (repeated factors: phase of repolarization (early or late), and location (left or right 148 ventricle). Activation times, repolarization times, heart rate, PR interval, QRS duration and 149 QT interval of zebra finch and mice were compared using an unpaired t-test. 


\section{Results}

$151 \mathrm{~J}$-waves and T-waves are concordant in zebra finches and discordant in mice.

152 We recorded and compared pseudo-ECGs ( $p E C G$ ) from Langendorff-perfused hearts of

153 zebra finch and mouse (Figure 2). All isolated hearts were spontaneously beating. Table 2

154 shows the ECG parameters for the zebra finch compared to the Mouse, which were

155 measured as depicted in Figure 1. The average heart rate in zebra finch was higher than that

156 of the mice, but this was not reach statistically significant (476 \pm 66 vs. $343 \pm 44, p=0.12$;

157 Table 2). Figure 2A shows typical examples of the six-lead pECG of the zebra finch (right)

158 compared to the mouse pECG (left). For the zebra finch, the QRS complex was negative in

159 lead I in three animals, positive in one animal and biphasic in one animal. In all mice, the

160 QRS complex was positive in lead I. QRS duration did not differ between species (Table 2). In

161 both species, the QRS complex was directly followed by a positive J-wave advancing into a T-

162 wave that intersected the isoelectric line on average at $65 \pm 4.9 \mathrm{~ms}$ after the onset of the QRS

163 complex in zebra finches or at $69.9 \pm 50 \mathrm{~ms}$ in mice. The vector cardiograms in Figure 2C\&D

164 show typical examples of the electrical heart axis of the mouse and zebra finch during

165 activation and repolarization. The J-wave (colored blue) was positive in lead I in both

166 species. In contrast, the T-wave (colored red) was concordant in all five zebra finches and

167 discordant in all five mice (although with a low amplitude).

\section{Epicardial activation and repolarization patterns}

170 Concordance between the J-wave and the T-wave is seen when early repolarization as well as late repolarization occur early. To determine the activation and repolarization patterns, we recorded optical action potentials during atrial pacing, in order to exclude an effect of cycle interval on repolarization. Figure $3 \mathrm{~A}$ shows a typical example of the epicardial activation pattern at the ventral ventricular surface of a zebra finch and a mouse heart. In the zebra finch, the activation front propagated from the left ventricle (LV) to the right ventricle (RV) culminating with the activation of the right ventricular outflow tract (RVOT). In the mouse, the activation front instead propagated from the apex. Epicardial breakthrough of the activation front in the LV occurred earlier in zebra finch than in mouse $(0.8 \pm 0.3$ vs $2.0 \pm 0.4 \mathrm{~ms}, p=0.046$ after the start of the QRS complex). However, as with QRS duration, total activation time did not differ between the zebra finch and the mouse (6.0 \pm 1.3 vs $5.8 \pm 0.3 \mathrm{~ms}, p=0.876)$.

In both zebra finches and mice, the pattern of early repolarization $(20 \%$ of repolarization, $\mathrm{RT20}$ ) followed the activation pattern (Figure 3B). Final early repolarization (RT20) was shorter in mice than in zebra finches (9.9 $\pm 0.4 \mathrm{~ms}$ vs $15.5 \pm 1.3 \mathrm{~ms}, p=0.002)$. In both species, final early repolarization occurred first in the LV apex and last in the RVOT $(15.5 \pm 1.3 \mathrm{~ms}$ vs $9.5 \pm 0.5 \mathrm{~ms}(\mathrm{p}=0.003)$ in zebra finch; $9.9 \pm 0.4 \mathrm{~ms}$ vs $7.6 \pm 2.2 \mathrm{~ms}(\mathrm{p}=0.041)$ in mouse). This generated a similar electrical vector, giving rise to the J-wave with similar polarities in the six-lead ECG (Figure 2). During repolarization, an electrical dipole with a negative front in the extracellular space is generated. This is opposite to the positive activation front, as illustrated by the opposed direction of the arrows in Figure 3. 
191 The pattern of late repolarization (RT80) differed markedly between mice and zebra 192 finches (Figure 3B). In zebra finches, late repolarization started $29.0 \pm 3.3 \mathrm{~ms}$ after onset of 193 the QRS in the LV free wall and ended 56.7 $\pm 1.6 \mathrm{~ms}$ after onset of the QRS in the RV free 194 wall. This pattern generated an electrical vector directed to the left side, leading to a 195 positive T-wave in lead I as observed in the $\mathrm{PECG}$. In mice, however, late repolarization 196 started $43.2 \pm 5.7 \mathrm{~ms}$ after onset of the QRS in the RV free wall and ended $51.6 \pm 2.6 \mathrm{~ms}$ after 197 onset of the QRS in the LV free wall. This generated an electrical vector directed towards the 198 right side, leading to a negative T-wave in lead I as observed in the PECG which is opposite 199 to our observations in zebra finches.

200 Figure 4 shows the relation between local early and late repolarization and the J- and 201 T-wave in zebra finch and mouse. In the zebra finch, both early and late repolarization occur 202 later in the RV compared to the LV, causing a positive J-wave and positive T-wave in lead I. 203 In mice, early repolarization occurs later in the right than LV, whereas late repolarization 204 occurs earlier in the RV compared to the LV (Figure 4A). This latter phenomenon gives rise 205 to a positive J-wave and negative T-wave in lead I. 


\section{Discussion}

207 We show that J-waves are not a unique to small mammals, but also occur in at least one 208 bird species. The zebra finch shows a J-wave, which results from early repolarization starting 209 in the LV and ending at the base of the RV. This early repolarization pattern resembles that 210 of mouse, supporting the hypothesis that early repolarization is present in animals with high 211 heart rates. Additionally, we found that late repolarization in the zebra finch heart starts in 212 the LV and ends in the RV leading to a positive T-wave, which is in contrast to mouse, and results in a T-wave with concordance to the J-wave.

Mammals and birds evolved independently from amniotes with hearts that likely were much like the hearts of extant reptiles (Jensen and Christoffels, 2020) and QT duration in mammals and birds is approximately four-fold shorter than in reptiles (Boukens et al., 2019). Early repolarization shortens the ventricular action potential and shorter action potentials allow for high heart rates. The presence of early ventricular repolarization in the zebra finch adds to the numerous features of convergent evolution between mammalian and avian hearts (Boukens et al., 2019; Kroneman et al., 2019). On the level of ion channels, early ventricular repolarization in the mouse is dependent on the currents $I_{\text {Kur }}$ and $I_{\text {to }}$ (Brouillette et al., 2004). It remains to be shown whether early ventricular repolarization in zebra finch is dependent on these same channels. There are multiple species of bird of which the ECG has been published and in which our conjecture that early repolarization of the heart ventricle always occurs in a setting of a high heart rate could be tested. Large birds as the Ostrich and Whooper swan have comparatively low heart rates, an isoelectric ST segment, and no J-wave (Machidad et al., 2001; Rezakhani et al., 2007). However, the ECGs of many birds studied, especially those with higher heart rates (>100 bpm), do not show a clear isoelectric ST segment and the $S$ deflection is often transitioned directly into the Twave (Nap, Lumeij and Stokhof, 1992; Machidad et al., 2001). We consider it likely that early repolarization contributed to the loss of the isoelectric ST segment, making it likely that early repolarization is a commonly occurring mechanism in birds by which high heart rates can be attained.

The J-wave in the zebra finch and mouse heart mainly results from early repolarization differences (RT20) between the base and the apex. Accordingly, the J-wave was positive in the same leads. The J-wave was discordant with the QRS complex in zebra finches but concordant with the QRS complex in mice (Figure 2). Concordance between QRS complex and J-wave (or T-wave) is caused by myocardium activating early but repolarizing late (Opthof et al., 2016). Based on the activation pattern and early repolarization pattern this is the case in both species. Nevertheless, the J-wave was discordant with the QRS complex in the zebra finch. We believe that understanding the polarity of the QRS complex can explain this apparent paradox. Transmural activation has been found to be an important 
subendocardium, which has activated before epicardial breakthrough occurs, starts when the whole ventricle has not yet been activated. Therefore, this early repolarization is obscured by the QRS complex (Boukens et al., 2013). The J-wave only becomes visible when activation has ended and the QRS complex disappears. From that moment on, the J-wave only represents the early repolarization difference between the base and the apex. In birds, the discrepancy between the epicardial activating pattern and QRS polarity is less. The first epicardial breakthrough occurs earlier in zebra finches than in mice likely reflecting almost simultaneous transmural activation of the ventricular wall, thereby resulting in discordance between the QRS-complex and the J-wave. Birds are known to have a transmural ventricular conduction system, that could underlie this simultaneous transmural activation (Davies and Francis, 1946; Kharin, Antonova and Shmakov, 2007).

Hearts of mammals and birds have a specialized ventricular conduction system causing fast activation of the ventricles (Davies and Francis, 1946). This is supported by our observations that both total activation time of the heart and QRS duration are not different between the zebra finch and mouse (Table 1). In mammals, distinct early activations on the ventral surface of the left and right ventricle are thought to reveal the presence of the left and right bundle branches of the His-Purkinje system (Sedmera, 2011), but such distinct early activations were not obvious in the zebra finches. Epicardial activation in the zebra finch starts in the left ventricular free wall and propagates towards the RV. The activation pattern is reflected by the negative QRS complex in lead I, which has long been recognized on the bird heart ECG (Whittow, 1999). We have detected similar epicardial activation patterns in hearts of alligators but the QRS duration in these animals is much longer (Jensen et al., 2018).

The T-wave was concordant with the J-wave in zebra finch but not in mouse. This is explained by the pattern of late repolarization which is from left to right in the zebra finch and from right to left in the mouse. We think that the direction of late ventricular activation does not play a role in enabling a higher heart rate because both final repolarization and QT time $(65.1 \pm 4.9$ vs $69.9 \pm 5.0 \mathrm{~ms}, p=0.31)$ are not different between the zebra finch and the mouse. Since activation differences between the ventricles are small, the repolarization pattern is mainly due to differences in action potential duration, which, indeed, was longer in the RV than LV in the zebra finch ( $49.7 \pm 2.3$ vs $28.0 \pm 3.2 \mathrm{~ms}$, respectively). It is remarkable that in the zebra finch action potential duration is much longer in the RV. In mammals, the action potential is substantially shorter in the myocardium of the RV than in the myocardium of the LV (Volders et al., 1999). One explanation for this is the relative lower pulmonary blood pressure, compared to the systemic blood pressure in mammals. However, when birds are compared to mammals, the systemic blood pressure is greater and the pulmonary blood pressure is lower (Whittow, 1999; Seymour and Blaylock, 2000). The left-right difference in ventricular pressure is therefore augmented in birds compared to mammals, yet this is not reflected in the action potential durations.

In humans, the prevalence of J-waves in ECGs varies between 5\% and 19\% (Offerhaus, Bezzina and Wilde, 2020). In the majority of cases these J-waves are benign. However, in 
288 some cases J-waves are a symptom of the early repolarization syndrome and are linked to

289 sudden cardiac arrest due to cardiac arrhythmias (Haissaguerre et al., 2008). The Brugada 290 syndrome is another arrhythmogenic pathology characterized by J-waves in the ECG.

291 Together, they are known as J-wave syndromes. It is thought that both syndromes share 292 early repolarization at a cellular level as a common mechanism underlying the J-waves in 293 the ECG and the occurrence of arrhythmias (Antzelevitch et al., 2016), although this has 294 been debated (Boukens, in press; Hoogendijk et al., 2010; Boukens, Opthof and Coronel, 295 2019). Another occasion when J-waves may occur, is during hypothermia or after cardiac 296 resuscitation which are then referred to as Osborn waves (Osborn, 1953; Jain et al., 1990). 297 Whether early repolarization at a cellular level causes these Osborn waves is unclear.

\section{Limitations}

300 Isolated heart preparations are disconnected from the autonomic nervous system. We 301 cannot exclude that autonomic modulation of repolarization has a role in shaping the J302 wave and T-wave in vivo. Moreover, it is debated whether the substances required for 303 recording optical action potentials, e.g. di-4-anneps and blebbistatin, affect local activation 304 and repolarization patterns and thereby the shape and duration of the T-waves (Fedorov et 305 al., 2007; Larsen et al., 2012; Kappadan et al., 2020). Nevertheless, a previous study of our 306 group showed that the pECG, recorded in the presence of blebbistatin and di-4-anneps, and 307 the in vivo ECG are comparable (Boukens et al., 2013). Furthermore, pECGs and optical 308 action potentials were recorded at $37^{\circ} \mathrm{C}$, which is $2-4^{\circ} \mathrm{C}$ below the normal body temperature 309 of the zebra finch, thereby possibly contributing to the J-wave in zebra finches (Skold-Chiriac 310 et al., 2015).

\section{Conclusion}

313 We show that early repolarization in the zebra finch heart causes J-waves in the ECG. This 314 resembles the phenotype in mice and supports the hypothesis that J-waves coincide with 315 higher heart rates. In small birds, early repolarization is likely a commonly occurring 316 mechanism in order to attain high heart rates. 
bioRxiv preprint doi: https://doi.org/10.1101/2020.07.20.211763; this version posted July 21, 2020. The copyright holder for this preprint (which

was not certified by peer review) is the author/funder, who has granted bioRxiv a license to display the preprint in perpetuity. It is made available under aCC-BY-NC-ND 4.0 International license.

\section{Acknowledgements}

320

321

\section{Competing interest}

322 The authors have no competing interest to declare.

323

324

325

Author contributions

326

327

328

329

330

$J A O, B J$ and BJB have performed the experiments and written the manuscript. PCS assisted with experimental procedures and edited the manuscript. JWF and KR have critically read and edited the manuscript.

\section{Funding}

BJB received funding from the Dutch Heart Foundation (2016T047).

332 
Table 1 - Body mass ( $\mathrm{kg}$ ), heart rate (beats per minute) and ST segment (in lead II) in birds.

\begin{tabular}{|c|c|c|c|c|c|}
\hline Species & Body mass & Heart rate & Anesthesia & $\begin{array}{l}\text { Clear } \\
\text { isoelectric } \\
\text { ST segment }\end{array}$ & Reference \\
\hline Ostrich & $\sim 100$ & 91 & No & Present & $\begin{array}{l}\text { (Rezakhani et } \\
\text { al., 2007) }\end{array}$ \\
\hline Emu & 41 & 69 & Yes $^{\#}$ & Present & $\begin{array}{l}\text { (Cushing et al., } \\
\text { 2013) }\end{array}$ \\
\hline Turkey & 14 & 206 & No & Present & $\begin{array}{l}\text { (Boulianne } e t \\
\text { al., 2015) }\end{array}$ \\
\hline Andean condor & 9.3 & 163 & No & Present & $\begin{array}{l}\text { (Wiemeyer } e t \\
\text { al., 2013) }\end{array}$ \\
\hline Whooper swan & 9.2 & 85 & No & Present & $\begin{array}{l}\text { (Machidad et } \\
\text { al., 2001) }\end{array}$ \\
\hline Griffon vulture & 6.4 & 160 & No & Absent & $\begin{array}{l}\text { (Talavera et al., } \\
\text { 2008) }\end{array}$ \\
\hline Pekin duck & 4 & 281 & No & Absent & $\begin{array}{l}\text { (Cinar et al., } \\
\text { 1996) }\end{array}$ \\
\hline Green peafowl & 4 & 258 & No & Present & $\begin{array}{l}\text { (Hassanpour, } \\
\text { Hojjati and } \\
\text { Zarei, 2011) }\end{array}$ \\
\hline Muscovy duck & 3 & 147 & No & Absent & $\begin{array}{l}\text { (Hassanpour } \\
\text { and Khadem, } \\
\text { 2013) }\end{array}$ \\
\hline Golden eagle & 2 & 347 & No & Absent & $\begin{array}{l}\text { Moghaddam } \\
\text { and Bashi, } \\
\text { 2010) }\end{array}$ \\
\hline $\begin{array}{l}\text { Helmeted Guinea } \\
\text { Fowl }\end{array}$ & 1.3 & 338 & No & Absent & $\begin{array}{l}\text { (Hassanpour, } \\
\text { Zarei and } \\
\text { Hojjati, 2011) }\end{array}$ \\
\hline Peregrine Falcon & 0.80 & 268 & No & Absent & $\begin{array}{l}\text { (Rodríguez et } \\
a l ., 2004 \text { ) }\end{array}$ \\
\hline Rook & 0.55 & 340 & No & Absent & $\begin{array}{l}\text { (Hassanpour et } \\
\text { al., 2016) }\end{array}$ \\
\hline Racing pigeon & 0.52 & 211 & No & Absent & $\begin{array}{l}\text { (Lumeij and } \\
\text { Stokhof, 1985) }\end{array}$ \\
\hline $\begin{array}{l}\text { Przevalski's } \\
\text { partridge }\end{array}$ & 0.51 & 317 & No & Present & $\begin{array}{l}\text { (Liu and Li, } \\
\text { 2005) }\end{array}$ \\
\hline Chukar partridge & 0.42 & 317 & No & Present & $\begin{array}{l}\text { (Uzun, Yildiz } \\
\text { and Onder, } \\
\text { 2004) }\end{array}$ \\
\hline $\begin{array}{l}\text { Pigeon (Spanish } \\
\text { Pouter) }\end{array}$ & 0.35 & 283 & No & Absent & $\begin{array}{l}\text { (Lopez Murcia } \\
\text { et al., 2005) }\end{array}$ \\
\hline Teal & 0.30 & 152 & No & Present & $\begin{array}{l}\text { (Machidad et } \\
\text { al, 2001) }\end{array}$ \\
\hline $\begin{array}{l}\text { Japanese quail } \\
\text { (male) }\end{array}$ & 0.14 & 460 & No & Absent & $\begin{array}{l}\text { (Szabuniewicz } \\
\text { and McCrady, } \\
\text { 2010) }\end{array}$ \\
\hline Laughing dove & 0.13 & 357 & No & Absent & $\begin{array}{l}\text { (Hassanpour } e t \\
\text { al., 2014) }\end{array}$ \\
\hline $\begin{array}{l}\text { Japanese quail } \\
\text { (female) }\end{array}$ & 0.12 & 320 & No & Absent & $\begin{array}{l}\text { (Szabuniewicz } \\
\text { and McCrady, } \\
\text { 2010) }\end{array}$ \\
\hline
\end{tabular}


bioRxiv preprint doi: https://doi.org/10.1101/2020.07.20.211763; this version posted July 21, 2020. The copyright holder for this preprint (which

was not certified by peer review) is the author/funder, who has granted bioRxiv a license to display the preprint in perpetuity. It is made available under aCC-BY-NC-ND 4.0 International license.

337

338 Table 2-ECG parameters for the zebra finch and Mouse. ${ }^{* *} p<0.01$

\begin{tabular}{lcccc} 
ECG parameter & $\begin{array}{c}\text { Zebra } \\
\text { finch }(\mathbf{n})\end{array}$ & $\begin{array}{c}\text { Mean } \\
\pm \text { s.e.m. }\end{array}$ & $\begin{array}{c}\text { Mouse } \\
(\mathbf{n})\end{array}$ & $\begin{array}{c}\text { Mean } \\
\pm \text { s.e.m. }\end{array}$ \\
\hline HR $(\mathrm{bpm})$ & 4 & $476 \pm 66$ & 5 & $343 \pm 44$ \\
PR $(\mathrm{ms})^{* *}$ & 4 & $51.8 \pm 5.2$ & 5 & $28.1 \pm 0.9$ \\
QRS $(\mathrm{ms})$ & 5 & $7.7 \pm 1.2$ & 4 & $8.2 \pm 0.4$ \\
QT $(\mathrm{ms})$ & 5 & $65.1 \pm 4.9$ & 5 & $69.9 \pm 5.0$ \\
\hline
\end{tabular}

339

340 
bioRxiv preprint doi: https://doi.org/10.1101/2020.07.20.211763; this version posted July 21, 2020. The copyright holder for this preprint (which was not certified by peer review) is the author/funder, who has granted bioRxiv a license to display the preprint in perpetuity. It is made available under aCC-BY-NC-ND 4.0 International license.

341

342

Figure 1

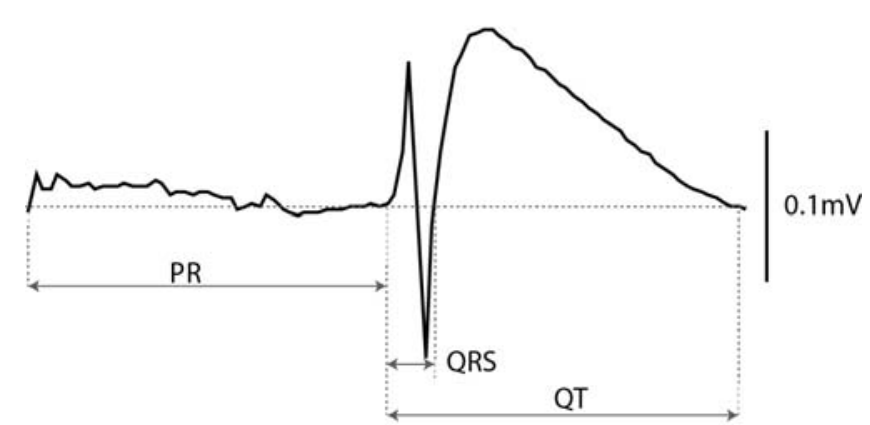

$100 \mathrm{~ms}$

344 Figure 1 - Lead I of the zebra finch ECG showing different ECG parameters.

345 


\section{Figure 2}

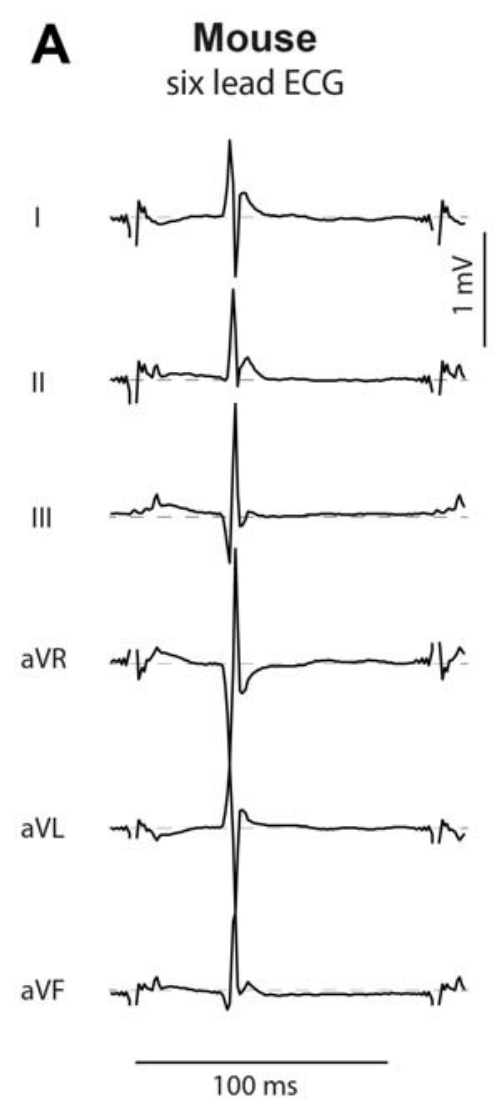

C

Mouse vector cardiogram

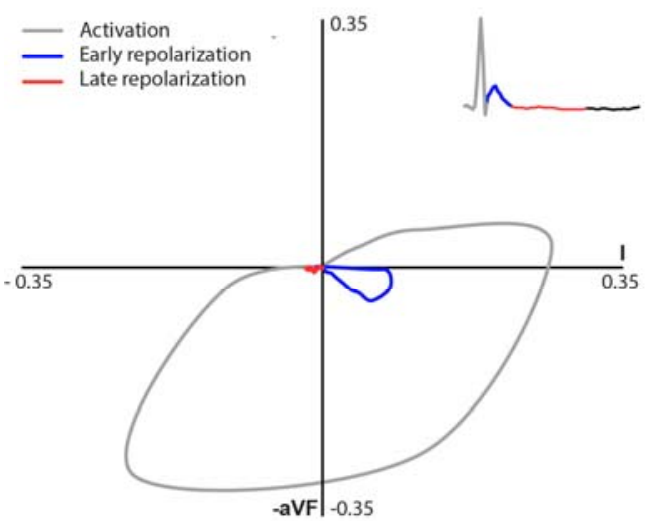
concordant in the zebra finch (D).

\section{B Zebra finch six lead ECG}

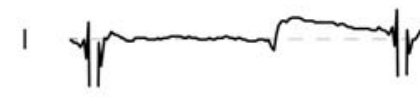

II

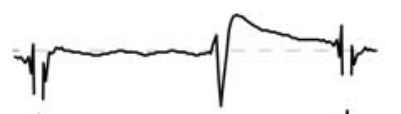

III<smiles>C=CCCCC</smiles>

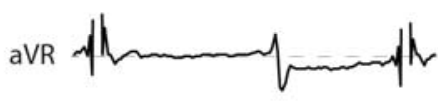
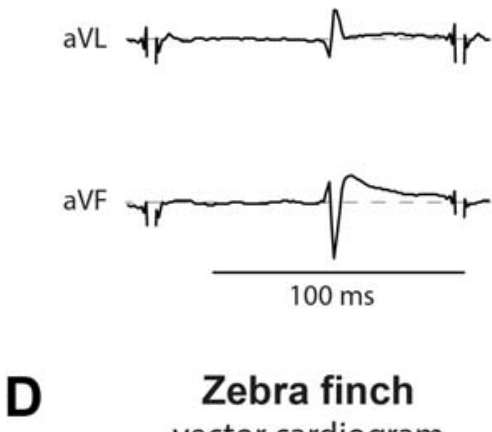

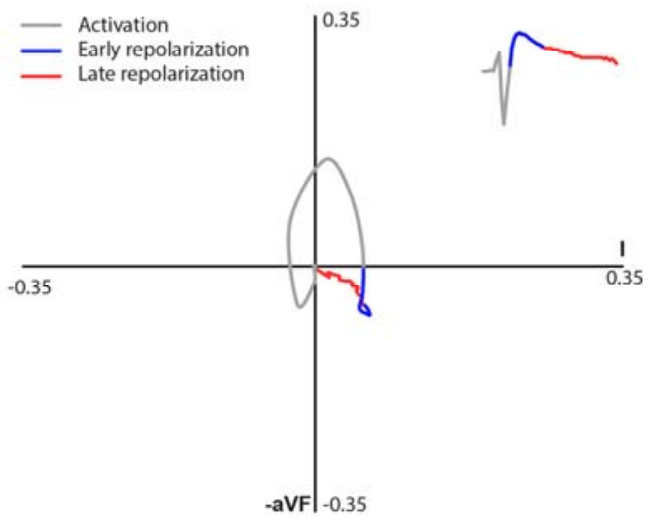

Figure 2 - Six-lead ECG and vector cardiograms for mouse and zebra finch: Contrary to mice, the J-wave and T-wave are concordant in the zebra finch. Typical example of a sixlead ECG in the mouse (A) and the zebra finch (B). Both animals show a positive deflection, the J-wave, directly following the QRS. The lower panel shows corresponding vector cardiograms ( $C$ and $D$ ). The direction of the early and late repolarizing electrical heart axes, characterized by the J-wave and T-wave respectively, are discordant in the mouse (C) and 


\section{Figure 3}

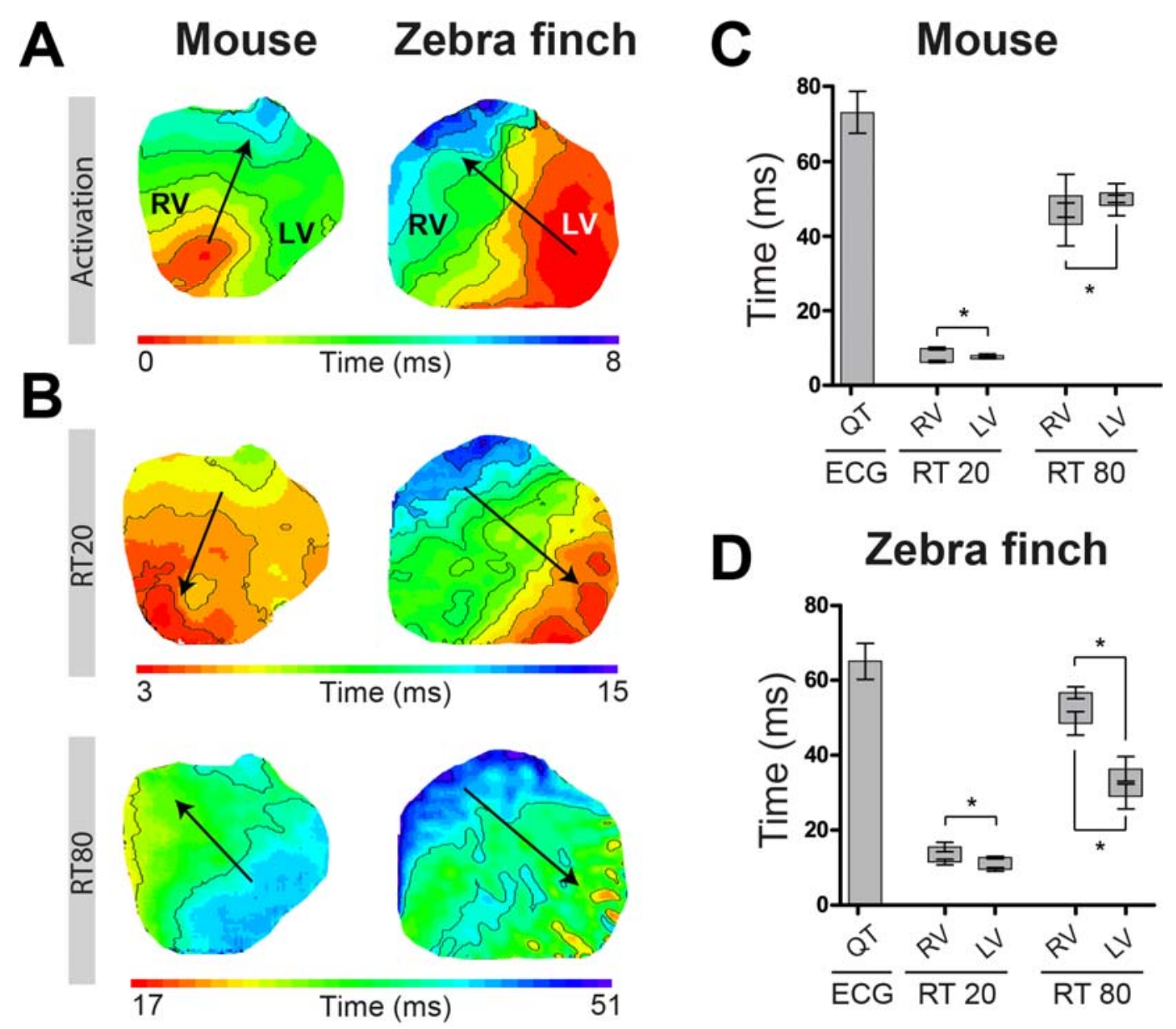

Figure 3 - The early- and late repolarization fronts follow the activation front in the zebra finch.

364 Typical activation (A) and repolarization (B) patterns in the mouse (left) and zebra finch 365 (right). The black arrows indicate the electrical vector that is generated by the activation and repolarization front. Early repolarization was defined by $20 \%$ of total repolarization (RT20) and late by $80 \%$ of total repolarization (RT80). The relationship between early and late repolarization in the right- and left ventricle in mice $(C, n=5)$ and zebra finches $(D, n=$ 3 ) is represented in the bar graphs. RV, right ventricle; LV, left ventricle. ${ }^{*} p<0.05$. 


\section{Figure 4}

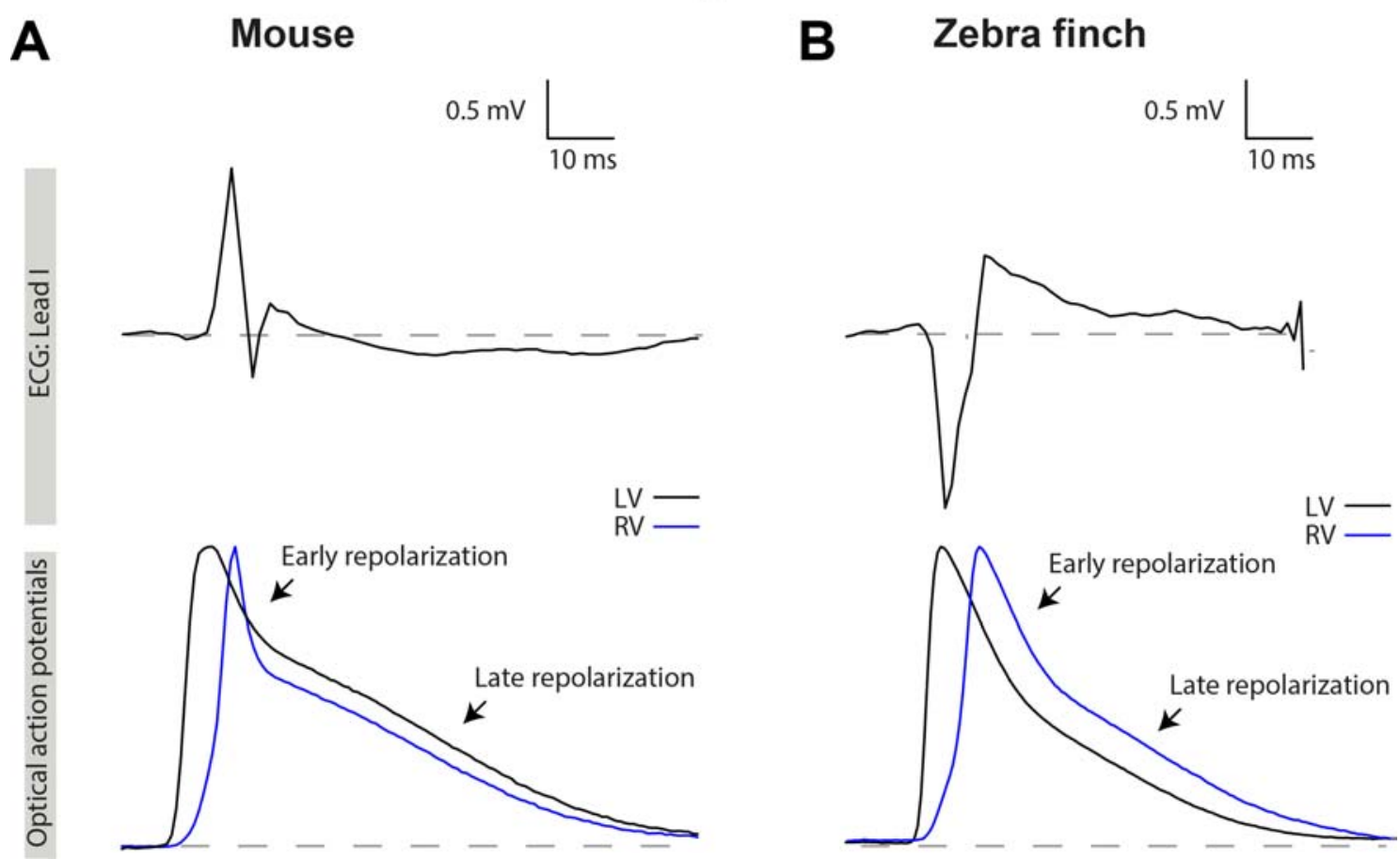

Figure 4 - The relation between the J-wave and T-wave results from the order of early and 376 late repolarization.

377 Lead I ECG traces aligned with optical action potentials from the LV (black) and RV (blue) in 378 the mouse (A) and zebra finch (B). The positive J-wave is the result of an early repolarization 379 front moving from LV to RV in both animals. In the zebra finch, late repolarization moves 380 from LV to RV, resulting in a concordant T-wave. In the mouse, however, the wave front 381 moves from RV to LV resulting in a concordant T-wave. LV, left ventricle; RV, right ventricle. 
385

386

387

388

389

390

391

392

393

394

395

396

397

398

399

400

401

402

403

404

405

406

407

408

409

410

411

412

413

414

415

416

417

418

419

420

421

422

423

424

425

426

427

428

429

430

431

\section{References}

Antzelevitch, C. et al. (2016) 'J-Wave syndromes expert consensus conference report:

Emerging concepts and gaps in knowledge', Europace, 19(4), pp. 665-694. doi:

10.1093/europace/euw235.

Bazett, H. (1920) 'An analysis of the time relations of electrocardiograms', Heart, 7, pp. 353370.

Boukens, B. J. et al. (2013) 'Early repolarization in mice causes overestimation of ventricular activation time by the QRS duration', Cardiovascular Research, 97(1), pp. 182-191. doi: 10.1093/cvr/cvs299.

Boukens, B. J. (no date) 'Structurally abnormal myocardium underlies ventricullar fibrillation storms in a patient diagnosed with the early repolarization pattern', JACC: Clinical Electrophysiology.

Boukens, B. J. D. et al. (2019) 'The electrocardiogram of vertebrates: Evolutionary changes from ectothermy to endothermy', Progress in Biophysics and Molecular Biology. Elsevier Ltd, 144, pp. 16-29. doi: 10.1016/j.pbiomolbio.2018.08.005.

Boukens, B. J., Opthof, T. and Coronel, R. (2019) 'J-Waves in Epicardial Electrograms Can Guide Ablation of Arrhythmogenic Substrates', Circulation Research, 124(2), pp. 205-207. doi: 10.1161/CIRCRESAHA.118.314414.

Boulianne, M. et al. (2015) 'Cardiac muscle mass distribution in the domestic turkey and relationship to electrocardiogram.', Avian diseases, 36(3), pp. 582-9. Available at:

http://www.ncbi.nlm.nih.gov/pubmed/1417589.

Brouillette, J. et al. (2004) 'Functional properties of $\mathrm{K}+$ currents in adult mouse ventricular myocytes', The Journal of Physiology, 559(3), pp. 777-798. doi: 10.1113/jphysiol.2004.063446.

Burggren, W., Farrell, A. and Lillywhite, H. (2011) 'Vertebrate Cardiovascular Systems', in Comprehensive Physiology. Hoboken, NJ, USA: John Wiley \& Sons, Inc. doi: 10.1002/cphy.cp130104.

Cinar, A. et al. (1996) 'The Electrocardiogram of the Pekin Duck', Avian Diseases, 40(4), p. 919. doi: $10.2307 / 1592317$.

Cooper, B. G. and Goller, F. (2006) 'Physiological insights into the social-context-dependent changes in the rhythm of the song motor program', Journal of Neurophysiology, 95(6), pp. 3798-3809. doi: 10.1152/jn.01123.2005.

Crossley, D. A. et al. (2016) 'Mass Transport: Circulatory System with Emphasis on Nonendothermic Species', in Comprehensive Physiology. Hoboken, NJ, USA: John Wiley \& Sons, Inc., pp. 17-66. doi: 10.1002/cphy.c150010.

Currie, S. E. (2018) 'No effect of season on the electrocardiogram of long-eared bats (Nyctophilus gouldi) during torpor', Journal of Comparative Physiology B. Springer Berlin Heidelberg, 188(4), pp. 695-705. doi: 10.1007/s00360-018-1158-1.

Cushing, A. et al. (2013) 'The electrocardiogram of anesthetized captive adult emus (Dromaius novaehollandiae)', Journal of Veterinary Cardiology. Elsevier B.V, 15(1), pp. 5156. doi: 10.1016/j.jvc.2012.11.001.

Davies, F. and Francis, E. (1946) 'The conducting system of the vertebrate heart', Biological Reviews. Biol Rev Camb Philos Soc, 21(4), pp. 173-188. doi: https://doi.org/10.1093/cvr/cvr062.

Durrer, D. et al. (1970) 'Total Excitation of the Isolated Human Heart', Circulation, 41(6), pp. 899-912. doi: 10.1161/01.CIR.41.6.899. 
432 Fedorov, V. V. et al. (2007) 'Application of blebbistatin as an excitation-contraction

433 uncoupler for electrophysiologic study of rat and rabbit hearts', Heart Rhythm. Heart

434 Rhythm, 4(5), pp. 619-626. doi: 10.1016/j.hrthm.2006.12.047.

435 Haissaguerre, M. et al. (2008) 'Sudden Cardiac Arrest Associated with Early Repolarization',

436 New England Journal of Medicine, 358(19), pp. 2016-2023. doi: 10.1056/nejmoa071968.

437 Hassanpour, H. et al. (2014) 'Normal electrocardiogram of the laughing dove (spilopelia

438 senegalensis)', Journal of Zoo and Wildlife Medicine, 45(1), pp. 41-46. doi: 10.1638/2012-

439 0256R.1.

440 Hassanpour, H. et al. (2016) 'Analysis of the Normal Electrocardiogram in Wild Rooks (

441 Corvus frugilegus )', Journal of Avian Medicine and Surgery, 30(4), pp. 329-334. doi:

442 10.1647/2015-079.

443 Hassanpour, H., Hojjati, P. and Zarei, H. (2011) 'Electrocardiogram analysis of the normal

444 unanesthetized green peafowl (Pavo muticus)', Zoo Biology, 30(5), pp. 542-549. doi:

$445 \quad 10.1002 / z 00.20357$.

446 Hassanpour, H. and Khadem, P. (2013) 'Normal Electrocardiogram Patterns and Values in

447 Muscovy Ducks ( Cairina moschata )', Journal of Avian Medicine and Surgery, 27(4), pp.

448 280-284. doi: 10.1647/2012-045.

449 Hassanpour, H., Moghaddam, A. K. Z. and Bashi, M. C. (2010) 'The Normal

450 Electrocardiogram of Conscious Golden Eagles (Aquila chrysaetos)', Journal of Zoo and

451 Wildlife Medicine, 41(3), pp. 426-431. doi: 10.1638/2009-0089.1.

452 Hassanpour, H., Zarei, H. and Hojjati, P. (2011) 'Analysis of Electrocardiographic Parameters

453 in Helmeted Guinea Fowl (Numida meleagris)', Journal of Avian Medicine and Surgery, 25(1),

454 pp. 8-13. doi: 10.1647/2009-048.1.

455 Hillman, S. S. and Hedrick, M. S. (2015) 'A meta-analysis of in vivo vertebrate cardiac

456 performance: implications for cardiovascular support in the evolution of endothermy',

457 Journal of Experimental Biology, 218(8), pp. 1143-1150. doi: 10.1242/jeb.118372.

458 Hoogendijk, M. G. et al. (2010) 'The Brugada ECG Pattern', Circulation: Arrhythmia and

459 Electrophysiology, 3(3), pp. 283-290. doi: 10.1161/CIRCEP.110.937029.

460 Jain, U. et al. (1990) 'Electrocardiographic J Waves after Resuscitation from Cardiac Arrest',

461 Chest, 98(5), pp. 1294-1296. doi: 10.1378/chest.98.5.1294.

462 Jensen, B. et al. (2018) 'Specialized impulse conduction pathway in the alligator heart', eLife.

463 NLM (Medline), 7. doi: 10.7554/eLife.32120.

464 Jensen, B. and Christoffels, V. M. (2020) 'Reptiles as a Model System to Study Heart

465 Development', Cold Spring Harbor Perspectives in Biology, 12(5), p. a037226. doi:

466 10.1101/cshperspect.a037226.

467 Kappadan, V. et al. (2020) 'High-Resolution Optical Measurement of Cardiac Restitution,

468 Contraction, and Fibrillation Dynamics in Beating vs. Blebbistatin-Uncoupled Isolated Rabbit

469 Hearts', Frontiers in Physiology. Frontiers Media SA, 11. doi: 10.3389/fphys.2020.00464.

470 Kharin, S. N., Antonova, N. A. and Shmakov, D. N. (2007) 'Transmural gradient of recovery of

471 excitability of the left ventricle myocardium of the chicken Gallus domesticus', Journal of

472 Evolutionary Biochemistry and Physiology, 43(1), pp. 116-118. doi:

473 10.1134/S0022093007010115.

474 Kroneman, J. G. H. et al. (2019) 'Comparative analysis of avian hearts provides little

475 evidence for variation among species with acquired endothermy', Journal of Morphology,

476 280(3), pp. 395-410. doi: 10.1002/jmor.20952.

477 Larsen, A. P. et al. (2012) 'The voltage-sensitive dye di-4-ANEPPS slows conduction velocity

478 in isolated guinea pig hearts', Heart Rhythm. Heart Rhythm, 9(9), pp. 1493-1500. doi: 
479

480

481

482

483

484

485

486

487

488

489

490

491

492

493

494

495

496

497

498

499

500

501

502

503

504

505

506

507

508

509

510

511

512

513

514

515

516

517

518

519

520

521

522

523

524

525 10.1016/j.hrthm.2012.04.034.

Laughner, J. I. et al. (2012) 'Processing and analysis of cardiac optical mapping data obtained with potentiometric dyes', AJP: Heart and Circulatory Physiology, 303(7), pp. H753-H765. doi: 10.1152/ajpheart.00404.2012.

Lillywhite, H. B., Zippel, K. C. and Farrell, A. P. (1999) 'Resting and maximal heart rates in ectothermic vertebrates', Comparative Biochemistry and Physiology Part A: Molecular \& Integrative Physiology, 124(4), pp. 369-382. doi: 10.1016/S1095-6433(99)00129-4. $\mathrm{Liu}, \mathrm{C}$. and $\mathrm{Li}, \mathrm{R}$. (2005) 'Electrocardiogram and heart rate in response to temperature acclimation in three representative vertebrates', Comparative Biochemistry and Physiology Part A: Molecular \& Integrative Physiology, 142(4), pp. 416-421. doi:

10.1016/j.cbpa.2005.09.008.

Liu, G. et al. (2004) 'In vivo temporal and spatial distribution of depolarization and repolarization and the illusive murine T wave', The Journal of Physiology. J Physiol, 555(1), pp. 267-279. doi: 10.1113/jphysiol.2003.054064.

Lopez Murcia, M. M. et al. (2005) 'The Normal Electrocardiogram of the Unanaesthetized Competition "Spanish Pouler" Pigeon (Columba livia gutturosa)', Journal of Veterinary Medicine Series A, 52(7), pp. 347-349. doi: 10.1111/j.1439-0442.2005.00723.x. Lumeij, J. . and Stokhof, A. A. (1985) 'Electrocardiogram of the Racing Pigeon (Columba Livia Domestica)', pp. 275-278.

Machidad, N. et al. (2001) 'Electrocardiography, Heart Rates, and Heart Weights of FreeLiving Birds', Journal of Zoo and Wildlife Medicine, 32(1), pp. 47-54. doi: 10.1638/10427260(2001)032[0047:ehrahw]2.0.co;2.

Nagel, A. (1986) 'The electrocardiogram of European shrews', Comparative Biochemistry and Physiology Part A: Physiology, 83(4), pp. 791-794. doi: 10.1016/0300-9629(86)90729-2. Nap, A. M. P., Lumeij, J. T. and Stokhof, A. A. (1992) 'Electrocardiogram of the African grey ( psittacus erithacus ) and Amazon ( Amazona spp.) parrot', Avian Pathology. Avian Pathol, 21(1), pp. 45-53. doi: 10.1080/03079459208418817.

Offerhaus, J. A., Bezzina, C. R. and Wilde, A. A. M. (2020) ‘Epidemiology of inherited arrhythmias', Nature Reviews Cardiology. Springer US, 17(4), pp. 205-215. doi: 10.1038/s41569-019-0266-2.

Opthof, T. (2000) 'Electrocardiogram of the normal mouse, Mus musculus General considerations and genetic aspects', Cardiovascular Research, 45(1), pp. 229-230. doi: 10.1016/S0008-6363(99)00334-X.

Opthof, T. et al. (2016) 'Dispersion in ventricular repolarization in the human, canine and porcine heart', Progress in Biophysics and Molecular Biology. Elsevier Ltd, 120(1-3), pp. 222-235. doi: 10.1016/j.pbiomolbio.2016.01.007.

Opthof, T. et al. (2017) 'Cardiac activation-repolarization patterns and ion channel expression mapping in intact isolated normal human hearts', Heart Rhythm. Elsevier B.V., 14(2), pp. 265-272. doi: 10.1016/j.hrthm.2016.10.010.

Osborn, J. J. (1953) 'Experimental Hypothermia: Respiratory and Blood $\mathrm{p}\langle\mathrm{scp}\rangle \mathrm{h}</ \mathrm{scp}\rangle$ Changes in Relation to Cardiac Function', American Journal of Physiology-Legacy Content, 175(3), pp. 389-398. doi: 10.1152/ajplegacy.1953.175.3.389.

Rezakhani, A. et al. (2007) 'A preliminary study on normal electrocardiographic parameters of ostriches (Struthio camelus)', Journal of the South African Veterinary Association, 78(1), pp. 46-48. doi: 10.4102/jsava.v78i1.286.

Rodríguez, R. et al. (2004) 'The Normal Electrocardiogram of the Unanesthetized Peregrine Falcon (Falco peregrinus brookei)', Avian Diseases, 48(2), pp. 405-409. doi: 10.1637/7123. 
526 Sedmera, D. (2011) 'Function and form in the developing cardiovascular system',

527 Cardiovascular Research. Cardiovasc Res, 91(2), pp. 252-259. doi: 10.1093/cvr/cvr062.

528 Seymour, R. S. and Blaylock, A. J. (2000) 'The Principle of Laplace and Scaling of Ventricular

529 Wall Stress and Blood Pressure in Mammals and Birds', Physiological and Biochemical

530 Zoology. Physiol Biochem Zool, 73(4), pp. 389-405. doi: 10.1086/317741.

531 Skold-Chiriac, S. et al. (2015) 'Body temperature changes during simulated bacterial

532 infection in a songbird: fever at night and hypothermia during the day', Journal of

533 Experimental Biology, 218(18), pp. 2961-2969. doi: 10.1242/jeb.122150.

534 Szabuniewicz, M. et al. (2010) 'The Electrocardiogram of the Capibara (Hydrochoerus

535 hydrochaeris, Linné) 1', Zentralblatt für Veterinärmedizin Reihe A, 25(2), pp. 162-171. doi:

536 10.1111/j.1439-0442.1978.tb00915.x.

537 Szabuniewicz, M. and McCrady, J. D. (2010) 'The Electrocardiogram of the Japanese

538 (Coturnix coturnix japonica) and Bobwhite (Colinus virginianus) Quail', Zentralblatt für

539 Veterinärmedizin Reihe A, 21(3), pp. 198-207. doi: 10.1111/j.1439-0442.1974.tb01112.x.

540 Talavera, J. et al. (2008) 'The normal electrocardiogram of four species of conscious raptors',

541 Research in Veterinary Science, 84(1), pp. 119-125. doi: 10.1016/j.rvsc.2007.03.001.

542 Uzun, M., Yildiz, S. and Onder, F. (2004) 'Electrocardiography of rock partridges (Alectoris

543 graeca) and chukar partridges (Alectoris chukar)', Journal of Zoo and Wildlife Medicine,

544 35(4), pp. 510-514. doi: 10.1638/02-056.

545 Volders, P. G. A. et al. (1999) 'Repolarizing K + Currents I TO1 and I Ks Are Larger in Right

546 Than Left Canine Ventricular Midmyocardium', Circulation. Lippincott Williams and Wilkins,

547 99(2), pp. 206-210. doi: 10.1161/01.CIR.99.2.206.

548 Whittow, G. C. (1999) Sturkie's avian physiology (5th ed.). Cambridge, Massachusetts:

549 Academic Press.

550 Wiemeyer, G. M. et al. (2013) 'Electrocardiography in conscious releasable andean condors (

551 Vultur gryphus ): Reference panel and unusual findings', Zoo Biology, 32(4), pp. 381-386.

552 doi: $10.1002 /$ zoo.21060.

553 